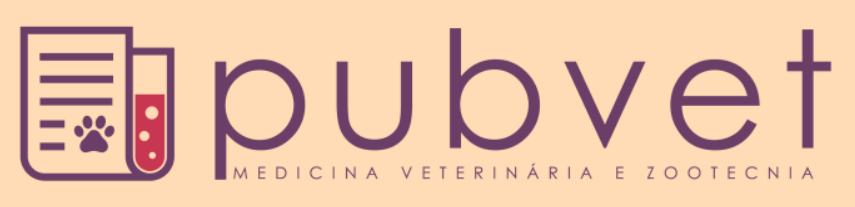

https://doi.org/10.22256/pubvet.v12n3a60.1-3

\title{
Toxicose por picada de abelhas em cão
}

\author{
Jéssica Maria da Silva Sousa 1 \\ 'Médica Veterinária Autônoma, Teresina, Piauí, Brasil, E-mail: jessicasousa 92@ hotmail.com
}

\begin{abstract}
RESUMO. Acidentes por picadas de abelhas em cães ocorrem com frequência, entretanto, há poucos casos descritos em literatura. Este relato descreve um caso fatal de um canino, com sinais de reação tóxica sistêmica decorrente de um acidente por abelhas. Os principais sinais clínicos foram hemólise e hemoglobinúria. Outros achados incluíram taquicardia e dispneia bem como a presença dos ferrões no corpo do animal. Apesar da instituição do tratamento clínico, o animal veio a óbito duas horas após.
\end{abstract}

Palavras chaves: abelha, anafilaxia, anemia hemolítica, cão, emergência

\section{Toxic infestation by bee sting in dog}

ABSTRACT. Accidents due to bee stings in dogs occur frequently, however, there are few cases described in the literature. This report describes a fatal case of a canine, with signs of systemic toxic reaction due to a bees accident. The main clinical signs were hemolysis and hemoglobinuria. Other findings included tachycardia, and dyspnoea as well as the presence of stings in the animal's body. Despite the institution of clinical treatment, the animal died two hours later.

Keywords: bee, anaphylaxis, hemolytic anemia, dog, emergency

\section{Intoxicación por picadura de abejas en perro}

RESUMEN. Los accidentes por picaduras de abejas en perros ocurren con frecuencia, sin embargo, hay pocos casos descritos en literatura. Este relato describe un caso fatal de un canino, con señales de reacción tóxica sistémica derivada de un accidente por abejas. Los principales signos clínicos fueron hemólisis y hemoglobinuria. Otros hallazgos incluyeron taquicardia y disnea, así como la presencia de los aguijones en el cuerpo del animal. A pesar de la institución del tratamiento clínico, el animal llegó a la muerte dos horas después.

Palabras claves: abeja, anafilaxia, anemia hemolítica, perro, emergência

\section{Introdução}

Acidentes por picadas de abelhas costumam ocorrer com certa frequência em cães (Machado et al., 2012). Entretanto existem poucos casos relatados em literatura. Em consequência disso, muita casos não são diagnosticados corretamente, ou não há compreensão do nível de comprometimento do organismo afetado (Machado et al., 2012, Maraschin, 2015). As abelhas possuem um órgão inoculador de veneno (ferrão) contendo glândulas veneníferas anexas (Arruda et al., 2007). Tais acidentes em animais domésticos podem resultar em reação de hipersensibilidade (reação alérgica) devido a picada ou em toxicose por várias picadas (reação tóxica sistêmica (Maraschin, 2015). O número de ferroadas e consequentemente a quantidade de veneno inoculado no animal constituem um importante fator com relação ao prognostico do animal. Distúrbios hemolítico tem sido incriminados como uma das principais complicações dos acidentes por picadas de abelhas, devido a lesão da membrana eritrocitária mediada por alguns componentes do veneno, desencadeando hemólise intravascular (Thrall, 
2007). A hemoglobinúria pode ser responsável pela necrose tubular aguda. Entretanto, alguns estudos relatam que talvez haja uma ação direta de alguns constituintes do veneno sobre as células do epitélio tubular renal (Fighera et al., 2007, Maraschin, 2015). Os sinais clínicos podem variar de eritema e edema até mesmo a sinais de reação sistêmica, como vômitos, diarreias, dificuldades respiratórias e choques. Casos de crise hemolítica também têm sido descritos (Fighera et al., 2007). $\mathrm{O}$ diagnóstico pode ser feito pela presença dos ferrões infiltrados na pele, boca, língua e até mesmo no esôfago, estômago e intestino delgado dos cães afetados, bem como o auxílio de exames laboratoriais como hemograma, bioquímicos, urinalise e até mesmo por necropsia (Machado et al., 2012). Não há antídoto contra o veneno da abelha, o tratamento é apenas sintomático. A remoção dos ferrões deve ser feita com um objeto plano e fino, evitando o aperto dos mesmos a fim de evitar liberação maior de veneno, o que pode agravar ainda mais o caso (Fragata \& Santos, $\underline{2008)}$.

Em casos de toxicose sistêmica e anafilaxia o uso de corticoide e anti-histamínico é preconizado. Quando se fizer necessário, a oxigenioterapia e a manutenção da pressão arterial devem ser empregadas. A reação pode variar de acordo com a quantidade de ferrões, uma vez que a crise hemolítica se instala rapidamente e o óbito advém (Machado et al., 2012, Maraschin, 2015).

\section{Caso clínico}

Foi atendido, no Hospital Veterinário Universitário da Universidade Federal do Piauí UFPI, no setor de urgências e emergências, um canino, SRD, fêmea, 8 meses de idade com o histórico de ter sido picado por um enxame de abelhas.O tutor relatou que o animal estava junto com outro filhote em um terreno quando percebeu a presença de várias abelhas sobre os mesmos. Segundo o proprietário, um dos filhotes veio há óbito em poucos minutos. O animal sobrevivente deu entrada no hospital veterinário apresentandose prostrado, com mucosas levemente hipocoradas, temperatura corporal de $37,5{ }^{\circ} \mathrm{C}$, taquicardia, dispneia e com múltiplos ferrões pelo corpo (Figura 1A). Prontamente foi instituído a oxigenoterapia por ventilação mecânica, fluido de Ringer Lactado na taxa de $10 \mathrm{ml} / \mathrm{kg} / \mathrm{h}$, morfina $(1 \mathrm{mg} / \mathrm{kg}) \quad \mathrm{IM}$, dexametasona $(1 \mathrm{mg} / \mathrm{kg}) \mathrm{IV}$, prometazina $(0,5 \mathrm{mg} / \mathrm{kg})$ IV e adrenalina $(0,01$ $\mathrm{mg} / \mathrm{kg}$ ) IV. Logo em seguida o animal foi colocado em um colchão térmico, aquecido as patas com algodão ortopédico e removido os ferrões (Figura 1B). Também foram coletados materiais para exames de hemograma cujo VG foi 27 , bioquímicos com significância de ureia $(60,1)$ e creatinina $(1,7)$ e urinalise, contudo, este não foi possível obter um resultado fidedigno por apresentar-se bastante hemolisado (Figura 2). O animal veio a óbito após 2 horas.

\section{Resultados e Discussão}

Lesões provocadas por abelhas costumam ocorrer com certa frequência em cães; porém existem poucos casos reportados na literatura científica. Embora seja um acidente de ocorrência comum, pouco se sabe sobre a patogênese dessa toxicose (Fighera et al., 2007). As manifestações clinicas costumam ser decorrentes da inoculação de substâncias vasodilatadoras presentes no veneno desses insetos que frequentemente cursam com rabdomiólise e crise hemolítica (França, 1994). Quando isso ocorre, a hemoglobinúria e mioglobinúria geram necrose tubular culminando em insuficiência renal aguda (Machado et al., 2012).

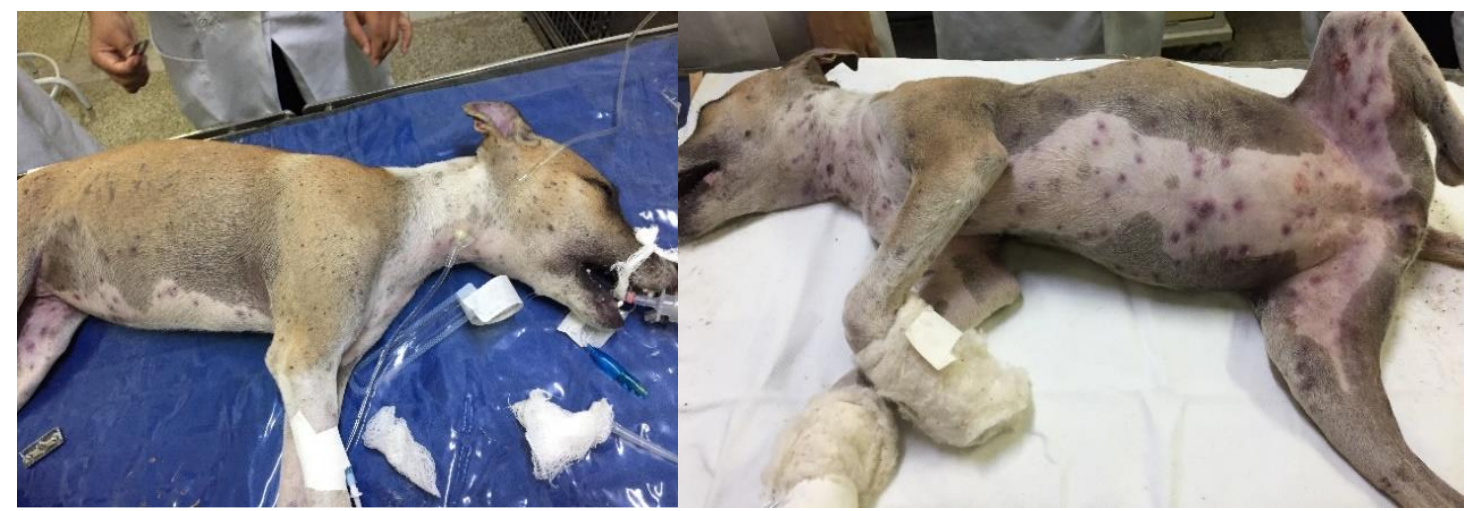

Figura 1. Lesão por picada de abelhas. A) Animal com ventilação mecânica e ferrões na pele. B) Lesões após a retirada dos ferrões 


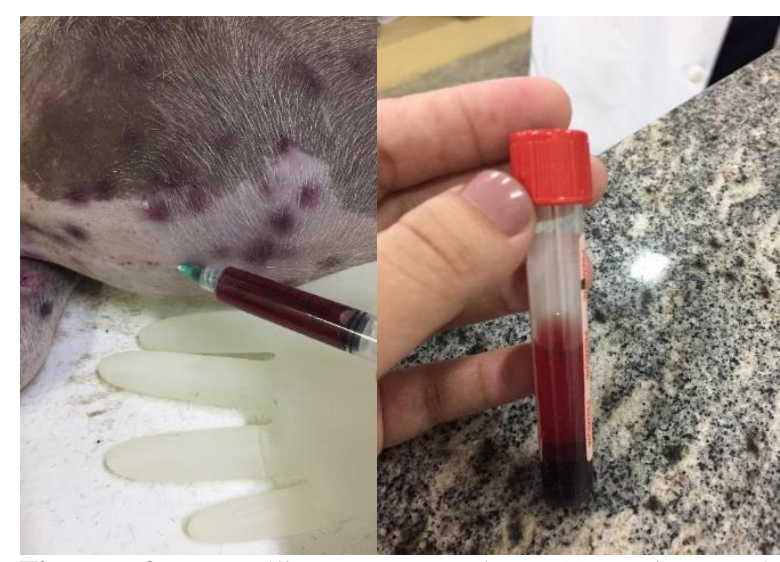

Figura 2. Hemólise Intravascular. A) Urina após cistocentese. B) Hemólise após centrifugação.

O exame de hemograma do paciente em questão apresentou anemia e trombocitopenia, sendo que os distúrbios hemolíticos são atribuídos às constituintes do veneno como as fosfolipase e melitina. As plaquetas baixas podem ser decorrentes da destruição imunomediada concomitante (síndrome de Evans) ou a coagulopatia intravascular disseminada (CID) (Thrall, 2007). A hemoglobinúria desenvolvida parece ter sido a causa do início da insuficiência renal aguda levando ao aumento discreto da ureia e creatinina. A presença dos ferrões encravados na pele do animal permitiu confirmar a observação do tutor e dos sinais clínicos apresentados, de que o animal havia sido atacado por enxame de abelhas. O sucesso no tratamento de um quadro agudo de anafilaxia depende da rapidez das ações emergências, acessando as vias aéreas e a circulação, com o objetivo principal da manutenção adequada dos sinais vitais (Machado et al., 2012). A adrenalina deve ser administrada na tentativa da manutenção da pressão arterial bem como na melhora da ventilação alveolar por dilatação dos brônquios (Machado et al., 2012). O corticoide atua no bloqueio antigeno-anticorpocomplemento reduzindo a produção de anticorpos e a ação dos macrófagos (Thrall, 2007). Mesmo com a instituição do protocolo adequado existe o risco de morte quando o animal é picado por várias abelhas em decorrência da reação tóxica. Todavia, o atendimento emergencial é um fator determinante no prognóstico favorável do paciente.

\section{Referências bibliográficas}

Arruda, V. M., Alves Jr, V. V., Moraes, M., Chaud Netto, J. \& Suárez, Y. R. 2007. Análise morfológica da glândula de veneno de Apis mellifera L. (Hymenoptera: Apidae) em populações de Mato Grosso do Sul. Neotropical Entomology, 36, 203-209.

Fighera, R. A., Souza, T. M. \& Barros, C. S. L. 2007. Acidente provocado por picada de abelhas como causa de morte de cães. Ciência Rural, 37, 590-593.

Fragata, F. S. \& Santos, M. M. 2008. Principais Conceitos em Medicina Veterinária Intensiva. Roca, São Paulo, Brasil.

França, F. O. 1994. Severe and fatal mas atacas by "killer" bees (Africanized honesto bees- Apis mellifera scutellata) in Brazil: clinicopathological studies with measurement of serum venom concentrations. Quarterly Journal of Medicine, 87, 269-288.

Machado, C., Silva, T. Z., Fernandes, C. P. M. \& Oliveira Nobre, M. 2012. Anafilaxia em cão por picada de abelhas. Acta Scientiae Veterinariae, 40, s1-s60.

Maraschin, D. K. 2015. Intoxicações em cães. Medicina Veterinária. Universidade Federal do Rio Grande do Sul, Porto Alegre, Rio Grande do Sul, Brasil.

Thrall, M. A. 2007. Hematologia e Bioquímica Clínica Veterinária. Editora Roca, São Paulo.

\section{Article History:}

Received 16 January 2018

Accepted 30 January 2018

Available online 27 February 2018

License information: This is an open-access article distributed under the terms of the Creative Commons Attribution License 4.0, which permits unrestricted use, distribution, and reproduction in any medium, provided the original work is properly cited. 